\title{
Hybrid coronary artery bypass grafting and transaortic transcatheter aortic valve implantation
}

\author{
Esther M. A. Wiegerinck, MD, Riccardo Cocchieri, MD, Jan Baan, Jr, MD, PhD, and \\ Bas A. J. M. de Mol, MD, PhD, Amsterdam, The Netherlands
}

Evolving less-invasive surgical techniques potentially minimize surgical trauma and reduce the risk of cardiac valve surgery. Transcatheter aortic valve implantation (TAVI) has emerged as an alternative for patients facing high or even prohibitive risk with conventional aortic valve replacement (AVR). Concomitant coronary artery disease (CAD) is a well-known comorbidity in degenerative aortic valve stenosis and has been identified as an independent factor for increased mortality in patients undergoing AVR. ${ }^{1}$ The presence of CAD in patients undergoing TAVI is estimated to be as great as $75.6 \%{ }^{2}$ Simultaneous percutaneous coronary intervention (PCI) has been reported although TAVI is currently considered a stand-alone procedure. Significant coexisting CAD requires preprocedural PCI.

In patients with significant complex CAD, rendering them ineligible for PCI, revascularization ideally consists of coronary artery bypass grafting (CABG). According to the current guidelines, patients undergoing $\mathrm{CABG}$ with at least moderate aortic stenosis should undergo concomitant AVR. Combining CABG and AVR increases procedural duration and is considered to increase operative mortality. ${ }^{3}$

High-risk patients with significant CAD who are ineligible for PCI could undergo surgical revascularization in a hybrid procedure with TAVI, reducing the duration of aortic crossclamping and cardiopulmonary bypass or even eliminating them entirely, thus decreasing surgical risk. Limited data are available regarding combined TAVI and surgical revascularization., ${ }^{4,5}$

We report TAVI through a transaortic approach during surgical revascularization in 5 high-risk patients with severe symptomatic aortic valve stenosis and significant CAD (Table 1).

From the Heart Center, Academic Medical Center-University of Amsterdam, Amsterdam, The Netherlands.

Disclosures: R.C. has a Proctorship with Edwards Lifesciences. All other authors have nothing to disclose with regard to commercial support.

Received for publication July 4, 2012; revisions received Sept 3, 2012; accepted for publication Sept 13, 2012; available ahead of print Oct 10, 2012.

Address for reprints: Riccardo Cocchieri, MD, Department of Cardio-thoracic surgery, Academic Medical Center, University of Amsterdam, Meibergdreef 9, 1105 AZ Amsterdam, The Netherlands (E-mail: r.cocchieri@amc.uva.nl).

J Thorac Cardiovasc Surg 2013;145:600-2

$0022-5223 / \$ 36.00$

Copyright (c) 2013 by The American Association for Thoracic Surgery

http://dx.doi.org/10.1016/j.jtcvs.2012.09.025

\section{CLINICAL SUMMARIES \\ First Patient}

In the past 3 years, 3 high-risk patients were treated with hybrid direct-vision TAVI and on-pump CABG.

The first was an 84-year old man with progressive dyspnea (New York Heart Association class III) as a result of severe symptomatic aortic valve stenosis and multiple comorbidities (including previous CABG) was referred for AVR. Routine preoperative coronary angiography revealed 2-vessel disease and an occluded venous graft. Operative mortality risk of a combined CABG and AVR reoperation was considered high (logistic EuroSCORE, $39.2 \%$; Society of Thoracic Surgeons [STS] score, 11.7\%).

\section{Second Patient}

An 80-year-old man with heart failure related to a severely calcified aortic valve stenosis was referred for AVR. Coronary angiography revealed bivascular CAD with a proximal left anterior descending coronary artery occlusion and a significant stenosis of the obtuse marginal branch of the circumflex coronary artery. Multiple comorbidities resulted in an operative mortality risk of $31.2 \%$ according to the logistic EuroSCORE and an STS score of $11.1 \%$.

\section{Third Patient}

A 79-year-old woman with multiple comorbidities and 3 previous PCIs was admitted for an acute myocardial infarction. Echocardiography showed diminished left ventricular function, with apical and septal akinesia and a severely stenotic aortic valve. Coronary angiography revealed stenosis of the main stem trifurcation. She was accepted for a highrisk emergency combined CABG and AVR (STS score, $32.4 \%$; EuroSCORE, 65.3\%).

\section{Procedure for First 3 Patients}

After median sternotomy, cardiopulmonary bypass was established by aortic and atrial 2-stage cannulation. Grafting was performed on the beating heart to shorten crossclamp time.

In the second patient, the proximal anastomosis was constructed with the Heartstring Proximal Seal System (Maquet Cardiovascular LLC, Wayne, NJ).

After surgical revascularization and antegrade blood cardioplegia, the ascending aorta was transversely incised. After excision of the aortic cusps, a transcatheter Edwards 


\begin{tabular}{|c|c|c|c|c|c|c|c|c|c|c|c|c|c|c|}
\hline \multirow[b]{2}{*}{ Case } & \multirow[b]{2}{*}{$\begin{array}{c}\text { Age } \\
(\mathbf{y})\end{array}$} & \multirow[b]{2}{*}{ Sex } & \multicolumn{4}{|c|}{ Preoperative data } & \multicolumn{3}{|c|}{ Scores } & \multicolumn{2}{|c|}{ Procedural data } & \multicolumn{3}{|c|}{$\begin{array}{c}\text { Postprocedural } \\
\text { echocardiography }\end{array}$} \\
\hline & & & $\begin{array}{l}\text { Presenting } \\
\text { symptom }\end{array}$ & $\begin{array}{l}\text { Peak TG } \\
(\mathrm{mm} \mathrm{Hg})\end{array}$ & $\begin{array}{l}\text { AVA } \\
\left(\mathrm{cm}^{2}\right)\end{array}$ & EF & SYNTAX & STS & EuroSCORE & Procedure & $\begin{array}{l}\text { Crossclamp } \\
(\text { min) }\end{array}$ & $\begin{array}{l}\text { Peak TG } \\
(\mathrm{mm} \mathrm{Hg})\end{array}$ & AR & EF \\
\hline 1 & 84 & M & Dyspnea & 55 & 0.9 & $37 \%$ & 34 & 11.1 & 33.5 & $\begin{array}{c}\text { CABG, direct-vision TAVI, } \\
\text { native valve excision }\end{array}$ & 35 & 7 & None & $45 \%$ \\
\hline 2 & 80 & M & $\begin{array}{l}\text { Heart } \\
\text { failure }\end{array}$ & 42 & 0.85 & $38 \%$ & 28 & 11.7 & 39.2 & $\begin{array}{c}\text { CABG, direct-vision TAVI, } \\
\text { native valve excision }\end{array}$ & 26 & 19 & Trivial & $48 \%$ \\
\hline 3 & 79 & $\mathrm{~F}$ & Acute MI & 40 & 0.9 & $26 \%$ & 45 & 32.4 & 65 & $\begin{array}{l}\text { On-pump CABG, } \\
\text { direct-vision TAVI, } \\
\text { native valve excision }\end{array}$ & 55 & 11 & Trivial & $24 \%$ \\
\hline 4 & 80 & $\mathrm{~F}$ & Angina & 77 & & $55 \%$ & 43 & 11.1 & 33.5 & Off-pump CABG, TAVI & None & 9 & None & $55 \%$ \\
\hline 5 & 78 & M & $\begin{array}{l}\text { Porcelain } \\
\text { aorta }\end{array}$ & 44 & 1.2 & $52 \%$ & 48 & 2.58 & 13.71 & Off-pump CABG, TAVI & None & & Mild & $45 \%$ \\
\hline
\end{tabular}

$T G$, Transaortic gradient; $A V A$, aortic valve area; $E F$, ejection fraction; STS, Society of Thoracic Surgeons; $A R$ : aortic regurgitation; $C A B G$, coronary artery bypass grafting; $T A V I$, transcatheter aortic valve implantation; $M I$, myocardial infarction; euroSCORE, European System for Cardiac Operative Risk Evaluation.

Sapien aortic bioprosthesis (Edwards Lifesciences, Irvine, Calif) was implanted under direct visualization by intraprosthetic balloon inflation. Coronary ostia were patent after implantation. Aortic crossclamp times were 35, 26, and 55 minutes, respectively. The aorta was closed with a running suture, and the circulation was restarted. All patients were weaned from cardiopulmonary bypass without difficulty.

\section{Postoperative Courses of First 3 Patients}

Postoperative transthoracic echocardiography revealed no intravalvular or paravalvular aortic regurgitation in the first patient. At 6 postoperative months, the AVA was 2.6 $\mathrm{cm}^{2}$, peak and mean gradients were 19 and $10 \mathrm{~mm} \mathrm{Hg}$.

Trivial paravalvular regurgitation was noted postoperatively on transthoracic echocardiography of the second and third patients. Left ventricular functions were similar to the preoperative situation. All patients initially recovered uneventfully. The first 2 patients were discharged on postoperative days 17 and 14 . The third patient unfortunately died of aspiration pneumonia with deterioration of her overall clinical status 3 weeks after the procedure.

\section{Fourth Patient}

An 80-year-old woman with multiple comorbidities and a recent cerebrovascular accident was referred for TAVI. She had undergone a previous PCI of the right coronary artery. Preoperative workup revealed a severely diseased left anterior descending coronary artery. Extensive tortuosity of the vessel prohibited PCI. An off-pump hybrid CABG with TAVI was scheduled. The patient's STS score was $11.1 \%$; her EuroSCORE was $33.5 \%$.

After median sternotomy, an off-pump left internal thoracic artery-left anterior descending coronary artery graft was constructed. Temporary epicardial pacemaker wires were placed. Two Prolene (Ethicon, Inc, Somerville, NJ)
2-0 purse-string sutures with polytetrafluoroethylene pledgets were placed on the ascending aorta. Balloon dilatation of the native aortic valve was followed by transcatheter implantation of an Edwards Sapien bioprosthesis $(26 \mathrm{~mm})$ under rapid pacing and fluoroscopic guidance. Echocardiography and angiography confirmed that the valve was functioning optimally.

Postoperative transthoracic echocardiography revealed no paravalvular regurgitation and a maximum pressure gradient of $9 \mathrm{~mm} \mathrm{Hg}$. The patient recovered uneventfully and was discharged 14 days after the procedure.

\section{Fifth Patient}

A 78-year-old man with progressive angina as a result of diffuse CAD was referred for CABG. Echocardiographic workup revealed moderate aortic valve stenosis and regurgitation. The patient was accepted for a combined CABG and AVR by our heart team. His STS score was $2.58 \%$; his EuroSCORE was $13.71 \%$.

Perioperatively, a porcelain aorta was found. Off-pump revascularization was successful, grafting the left internal thoracic artery to the left anterior descending coronary artery and grafting the diagonal obtuse marginal with saphenous vein graft, with the Heartstring used for the proximal anastomosis. Subsequent, 2 pledgeted purse-string sutures were taken onto an area without calcification on the ascending aorta, allowing direct sheath insertion in a straight line for device deployment. A transcatheter 26-mm Edwards Sapien valve was implanted under fluoroscopic guidance. After implantation, balloon postdilatation was performed to reduce paravalvular leakage.

Postprocedural echocardiography revealed good valvular function with mild paravalvular leakage. At day 6 , the patient was discharged from the intensive care unit; however, his hospital stay was extended because of development of compartment syndrome, and he was discharged 30 days later. 


\section{DISCUSSION}

Combined AVR with CABG and TAVI with PCI are current treatment options for aortic valve stenosis with concomitant CAD. Currently, treatment strategies are guided by operator preference and very limited data. At our institution, $\mathrm{PCI}$ is performed before TAVI in eligible patients with $\mathrm{CAD}$, followed by symptom reevaluation. It is evident however, that combined AVR with CABG and TAVI with PCI are less than ideal options for high-risk patients with complex multivessel CAD.

The success of the first hybrid surgical revascularization and TAVI with reduction of crossclamp and bypass times 3 years ago encouraged us to apply this technique in extremely high-risk patients. Optimizing the procedure resulted in an off-pump complete surgical revascularization with an aortic no touch technique combined with transaortic TAVI without aortic crossclamping and cardiopulmonary bypass in the most recent 2 cases. This procedure potentially provides an alternative treatment option for patients with prohibitively complex anatomy for a combined CABG and AVR.

Excision of calcified leaflets, as described in the first 3 cases, could potentially reduce paravalvular leakage and expand the indication for TAVI to aortic regurgitation without valvular calcification.

\section{CONCLUSIONS}

The described hybrid procedure, combining transaortic TAVI and off-pump CABG with the aortic no touch technique, shows promising outcomes and potentially provides an alternative to combined high-risk AVR and surgical revascularization. To our knowledge, this is the first successful implantation of a balloon-expandable transcatheter valve with native valve excision, potentially reducing paravalvular leakage and possibly expanding the indication for TAVI to aortic regurgitation without valvular calcification.

\section{References}

1. Langanay T, Flécher E, Fouquet O, Ruggieri VG, De La Tour BL, Félix C, et al. Aortic valve replacement in the elderly: the real life. Ann Thorac Surg. 2012;93: 70-7; discussion 77-8.

2. Dewey TM, Brown DL, Herbert MA, Culica D, Smith CR, Leon MB, et al. Effect of concomitant coronary artery disease on procedural and late outcomes of transcatheter aortic valve implantation. Ann Thorac Surg. 2010;89:758-67; discussion 767.

3. Nowicki ER, Birkmeyer NJ, Weintraub RW, Leavitt BJ, Sanders JH, Dacey LJ, et al. Multivariable prediction of in-hospital mortality associated with aortic and mitral valve surgery in Northern New England. Ann Thorac Surg. 2004;77: 1966-77.

4. Mandegar MH, Nazeri I, Abdi S, Roshanali F. Successful transcatheter aortic valve implantation through ascending aorta and total revascularization using Edwards SAPIEN Transcatheter Heart Valve System. Ann Thorac Surg. 2011;92:2262-3.

5. Santarpino G, Pfeiffer S, Fischlein T. Off-pump coronary artery bypass grafting in combination with transaortic transcatheter aortic valve implantation: a possible approach for patients with associated diseases. Int J Cardiol. 2012;157:e7-8.

\title{
Intraoperative transesophageal echocardiographic guidance for robotically assisted coronary sinus atrial septal defect repair
}

\author{
Linda Lau, MD, ${ }^{\text {a }}$ Kimberly Howard-Quijano, MD, ${ }^{a}$ Richard Shemin, MD, ${ }^{\mathrm{b}}$ and Aman Mahajan, MD, PhD, ${ }^{\mathrm{a}}$ \\ Los Angeles, Calif
}

Atrial septal defect (ASD) accounts for 10\% of congenital heart disease and $20 \%$ to $40 \%$ of cases presenting in adulthood. ${ }^{1}$ There are 4 categories: ostium secundum, ostium primum, sinus venosus, and coronary sinus defects. Coronary sinus defects, caused by incomplete formation of the

\footnotetext{
From the Departments of Anesthesiology ${ }^{\mathrm{a}}$ and Cardiothoracic Surgery, ${ }^{\mathrm{b}}$ the David Geffen School of Medicine, University of California, Los Angeles (UCLA), Los Angeles, Calif.

Disclosures: Authors have nothing to disclose with regard to commercial support.

Received for publication June 6, 2012; revisions received Aug 19, 2012; accepted for publication Sept 12, 2012; available ahead of print Oct 5, 2012.

Address for reprints: Kimberly Howard-Quijano, MD, Department of Anesthesiology, David Geffen School of Medicine at UCLA, 757 Westwood Plaza, Suite 3304, Los Angeles, CA 90095-7403 (E-mail: khquijano@mednet.ucla.edu). J Thorac Cardiovasc Surg 2013;145:602-4

$0022-5223 / \$ 36.00$

Copyright (c) 2013 by The American Association for Thoracic Surgery

http://dx.doi.org/10.1016/j.jtcvs.2012.09.014
}

atrioventricular folds, are the least common and are often associated with other congenital anomalies, including persistent left-sided superior vena cava (LSVC; Figure 1 ). ${ }^{2}$ Definitive treatment of a large coronary sinus defect is typically performed as an open surgical repair. We report the case of a patient with a coronary sinus defect in whom intraoperative transesophageal echocardiography (TEE) was instrumental in guiding robotically assisted surgical repair.

\section{CLINICAL SUMMARY}

A 40-year-old woman was seen with new-onset palpitations and shortness of breath. Preoperative transthoracic echocardiography and TEE demonstrated a $1.3-\mathrm{cm}$ primum ASD with a left-to-right shunt, dilated right ventricle, and pulmonary hypertension. Because of the defect's location, 